\title{
Second Language Learners' Performance and Strategies When Writing Direct and Translated Essays
}

\author{
Sadiq Abdulwahed Ahmed Ismail ${ }^{1} \&$ Negmeldin Omer Alsheikh ${ }^{1}$ \\ ${ }^{1}$ Faculty of Education, United Arab Emirates University, P. O. Box 17551, Alain, United Arab Emirates \\ Correspondence: Sadiq Abdulwahed Ahmed Ismail, Faculty of Education, United Arab Emirates University, P. \\ O. Box 17551, Alain, United Arab Emirates. Tel: 971-504-497-088. E-mail: ism232@gmail.com
}

Received: June 2, 2012 Accepted: June 18, 2012 Online Published: August 23, 2012

doi:10.5539/ies.v5n5p173 URL: http://dx.doi.org/10.5539/ies.v5n5p173

\begin{abstract}
The purpose of this study was to investigate ESL students' performance and strategies when writing direct and translated essays. The study also aimed at exploring students' strategies when writing in L2 (English) and L1 (Arabic). The study used a mixture of quantitative and qualitative procedures for data collection and analysis. Adapted strategy questionnaires, writing essay prompts and follow-up questions were utilized for data gathering. Thirty six university students participated in writing three different essays (direct L2 essay, L1essay, and translated essay). Furthermore, the participants responded to strategy questionnaires and answered follow-up questions. The results revealed statistically significant differences between direct and translated writing in favor of the first one. No significant differences between direct and translated writing in the use of strategies were found. The study's findings may have pedagogical implications for the fields of writing instruction, writing assessment and teacher training. Based on the results, the study ended with some recommendations to assist and direct future research.
\end{abstract}

Keywords: writing, direct, essay, translated, strategy, composition

\section{Introduction}

Motivated by the limitation of previous studies in the area of direct vs. translated writing within Arab ESL learners' contexts, this research paper aims at investigating students' performance and strategies when writing directly in English and when first composing in L1 and then translating into English. Learning to write effectively in a second language has represented a real difficulty for many students of English as a second language (ESL) for decades. Writing in L2 is considered not only a challenging practice but also a complex process (Wolfersberger, 2003). ESL writers find writing more challenging than other language skills as composing in the second language demands a number of cognitive and linguistic processes and strategies. A number of studies have examined the influence of writing first in the L1 and then translating into another language (Kobayashi and Rinnert, 2008, 1992; Cohen and Brooks-Carson, 2001; Uzawa, 1996). These studies have reported that students with limited language proficiency might benefit from writing first in their L1 and then translate their work into a second language. The influence of L1 in L2 writing is immanent especially for older ESL learners. L1 always impacts L2 writing as adult ESL students have already developed their writing skills and experience in their first language. Arab students, for instance, tend to transfer the culture of their L1 writing conventions into their L2 writing. Although the writing conventions and style of Arabic language are different in some ways from the English ones, students are always tempted to use them in L2 writing. Their writing is found to be longer, indirect and it includes some repetition (Abu Rass, 2011; Al-Khatib, 2001; Khuwaileh and Shoumali, 2000). In brief, L1 plays a significant role in the acquisition and learning of ESL writing and therefore a careful attention should be paid to first language when planning and/or designing a writing program.

\section{Research Questions}

1) Are there any significant differences between students' language use in writing directly in English and translated writing from the first language?

2) Are there any significant differences between students' use of writing strategies in L2 and L1? 
3) What do students consider to be the relevant advantages and disadvantages of the direct and translated writing modes?

4) What are the most common strategies students reported to use more frequently during the process of writing the translated essay?

\section{Literature Review}

Extending the line of previous research in the field of second language writing, this study examined students' writing achievements and strategies when writing directly in English and when writing first in L1 and then translating into English. ESL writers find writing more challenging than other language skills as composing in the second language demands a number of cognitive and linguistic processes and strategies. Zainuddin and Moore (2003) pointed out that the notion of culturally constructed rhetorical traditions and patterns is one of the key challenges that has been indicated by contrastive rhetoric studies. Baker (2008) argued that sociocultural and critical theories are fundamental for ESL instructors to understand how multilingual and multicultural students approach various writing tasks. It is believed that L2 writers may have different culturally-driven assumptions about academic writing in the L1 that may not be transferred directly to L2 writing (Connor, 2002; Dyc, 2002; Leki, 2000; Ramanathan and Kaplan, 1996). Consequently, writing should receive more attention in ESL classes in order to prepare the learners to cope with the communicative demands of real life situations. Undoubtedly, the purpose of teaching writing skill is to prepare ESL learners to become better writers. Exposing them to the writing process itself has been viewed as a better way for achieving this goal (Ismail, 2011). However, the influence of L1 cannot be completely ignored when teaching students to write in L2.

Research dealing with both L1 and L2 writing has reported different findings. A number of research results revealed some similarities between L1 and L2 writing and the importance for employing these similarities to enhance L2 writing skill (Alsamadani, 2010; Xiao-xia, 2008; Kamimura, 2001). Nevertheless, other research findings reported some differences between writing in L1 and L2 (Kohro, 2009; Zare-ee and Farvardin, 2009; McCarthey, et al., 2005; Martinez, 2005). Within the context of Arabic language writing, Alsamadani (2010) examined whether a relationship exists between Saudi students' English writing competence, their Arabic writing proficiency and their self-regulation skills when conducting a writing task. He reported that Saudi ESL students tend to use the same self-regulation when they write in both L1 (Arabic) and L2 (English). Additionally, it was found that those students who obtained high scores in both language writing tasks managed to demonstrate high achievements in their self-regulation skills. In their study about linguistics and rhetorical patterns, Zare-ee and Farvardin (2009) tried to examine whether there was significant differences between students' writing performance in L1 (Persian) and L2 (English). A summary of their findings indicated that there were significant differences in length, structure complexity and accuracy between L1 and L2 writing.

In relation to the use of L1 and/or L2 during the process of writing, researchers discussed whether second language writers use L1 or L2 to think when producing a piece of writing (Stapa and Abdulmajid, 2009; Weijen et al., 2009; Wang and Wen 2002; Cohen and Brooks-Carson, 2001). Thus, the issue whether ESL students think directly through the second language or through translating from the first language while writing generated some interesting research (Woodall, 2002; Wang, 2003). The majority of studies that have compared first language and second-language writing have found that there are similarities among the strategies used for both L1 and L2 processes (Jones and Tetroe, 1987; Uzawa and Cumming, 1989; Qi, 1998). These studies along with others reported the possibility of transferring writing strategies from L1situations to L2 contexts. Qi (1998), for example, found that the woman in the study switched to the L1 when capturing the beginning of an idea, when developing a thought, when verifying lexical meaning, and when her working memory was overloaded. It was also revealed that the tasks used in the study required a high level of knowledge and they were also associated with language switches. The researcher concluded that such tasks may even have the power to provoke language switches. In a study about switching to first language among writers with differing second-language proficiency, Wang (2003) reported that the frequencies of students' switching from one language to another slightly vary depending on their language proficiency. It was concluded that second language proficiency might impact student writers' procedures, quality of thinking and cognitive strategies when writing in L2. Within the same direction, Stapa and Abdulmajid (2009) reported that students who initially used their L1 to generate ideas demonstrated better performance when they composed their essay in L2.

A number of earlier L2 writing studies have also examined whether L2 students use L1 while writing in L2 though the influence imposed by L1 on L2 writing was somehow not clear (Friedlander, 1990; Krapels, 1990; Uzawa, 1996; Woodall, 2002). Those studies reported that L2 writers use their LI while writing in ESL. Similarly, other researchers have confirmed the same results that ESL writers use their first language while 
writing in their L2 for a number of purposes, such as planning (Beare, 2000; Wang, 2003; Woodall, 2002), generating ideas or content (Beare, 2000; Beare and Bourdages, 2007; Woodall, 2002), or solving linguistic problems such as vocabulary issues (Beare, 2000; Wang, 2003; Woodall, 2002). Moreover, some other studies investigated the possible effect of task features (such as topic knowledge or cultural factors) on L1 use and text quality during L2 writing, but they all failed to find a significant effect of planning during prewriting in the L1 or the L2 on text quality (Akyel, 1994; Lally, 2000).

Another factor that impacts L2 writing is referred to in the literature as a culture transfer. The transfer of L1 culture into L2 writing is based on some theoretical development such as the contrastive analysis model (Lei, 2008; Xiao-Zia, 2008). It was found that the negative transfer of L1 exceeded the positive one in L2 writing. L1 always impacts L2 writing as adult ESL students have already developed their writing skills and experience in their first language.

Cultural transfer in the context of Arabic language speakers has captured the attention of very few researchers in the area of ESL writing (Abu Rass, 2011; Al-Khatib, 2001; Khuwaileh \& Shoumali, 2000). According to Abu Rass (2011), transferring cultural norms and/or behavior is expected to take place when Arab students start to write in English as they are most of the time reverting to their stored experience and use it in their writing. She argued that cultural interference represents a real problem for Arab students to enhance their writing skill in English. Abu Rass (2011) concluded that L1 culture plays a key role in the second language acquisition and learning and hence it should be given a higher consideration when planning an ESL program. Khuwaileh \& Shoumali, (2000) indicated that Arab students are more likely to brainstorm their thoughts or ideas and prepare them first in their mother tongue before they start using English to translate and write them down. Some other support for the issue of cultural transfer was also found in Al-Khatib's (2001) study about wring personal letters in English by Jordanian Arab students. The overall findings revealed that Arab students transfer the style and mode of writing letters in Arabic into L2 writing. Many Arab student writers tend to be indirect in their expression and they write detailed or long introduction. They are mainly influenced by their sociolinguistic background and they may assume that their audience shares the same experience with them. Al-Khatib (ibid) also found that religious factors play crucial role in the convention of writing personal letters in Arabic.

The issue of using translation and thinking in the first language while writing in English has also attracted the attention of a number of researchers (Kobayashi and Rinnert, 2008; Cohen and Brooks-Carson, 2001; Uzawa, 1996; Wolfersberger, 2003; Weijen, Bergh, Rijlaarsdam, and Sanders, 2009; Wang and Wen, 2002; Kobayashi, and Rinnert, 1992). Some of those researchers, such as Cohen and Brooks-Carson (2001) focused on the direct versus translated writing and the strategies used by students when writing directly in L2 and/or when writing first in L1 and then translating into L2. The question posed by Cohen and Brooks-Carson (2001) is that whether thinking through the first language and even writing out a text first in the L1 may actually enhance quality writing production in L2. The researchers found that two-thirds of the students performed better in the direct-writing task and one-third of the students did better in the translated writing task. Another finding was that grammar rating across writing modes was not found to be significantly different. The students also reported that they thought in English most of the time while they were writing their essays. Cohen's and Brooks-Carson's (ibid) study draws attention to the different ways that students may employ for using their first language when they are writing a translated essay in L2.

In a study about the use of translation, Uzawa (1996) reported results in favor of the translated assignments. Twenty two Japanese students studying ESL in Canada participated in the study. All students were asked to perform three tasks (writing direct essay in L2, writing an essay in L1 and then translating it into L2). Thinking Aloud Protocol, interview techniques and writing samples were the main tools used for collecting data. Uzawa (1996) reported that students showed better use of the language in the translated essay than they did in the L1essay and the direct essay. Also the attention patterns in the direct and L1 tasks were found to be similar but they were different in the translated task. In their study, Wang and Wen (2002) confirmed that the L2 writing process is a bilingual event since the second language writers have two languages (L1 and L2) at their disposal when they are attempting to compose a text in L2. However, the central problem is that it is not clear how the use of L1 is related to the occurrence of different cognitive activities in a second language writing, such as planning and generating ideas. The reason behind first language use and the type of cognitive activities employed while writing is still not clear.

The area of language learning strategies in general and writing strategies in particular have recently received some attention. A number of studies were conducted to explore effective language and writing strategies and their benefits to improve students' performance (Ismail, 2011; Roca de Larios, Manchon and Murphy, 2008; Sasaki, 2004, 2007; Wong, 2005; Casanave, 2002; Lv and Chen, 2010; Griffiths, 2007; Wenyu and Yang, 2008). 
Strategies refer to learners' efforts to exploit a variety of procedures and actions for the purpose of learning and/or using a foreign or a second language (Zhang and Goh, 2006). Those strategies are classified into four different sets according to whether they are cognitive, social, affective or metacognitive (Cohen 1998). This particular classification is recognized to be a popular framework for categorizing and studying the strategies used to learn certain skills. In the area of language strategy, Griffiths (2007) investigated both the reported frequency of strategies used by ESL students and teachers' views of the importance of using such strategies. The findings of this study revealed that teachers regard the use of strategies as highly important for better achievements. It was also found that there is a strong relationship between those strategies students reported using highly frequently and those strategies seen by teachers as highly important for learning.

In the area of cognitive strategies, Lv and Chen (2010) investigated the effect of metacognitive strategies training on students' writing performance in a vocational college. Metacognitive experience in writing is seen to include emotional experience and cognitive experience. The cognitive experience helps students during the process of writing monitor and redirect their efforts through self-questioning. Emotional experience assists in elevating students' interests, motivation and desire to produce a good piece of writing. Lv and Chen (ibid) found that the teaching method, which encourages the use of metacognitive strategies, has an impact on students' writing performance. In an interesting study about writing strategies of Chinese EFL students, Wenyu and Yang (2008) investigated the relations among writing strategies, writing proficiency and writing scores. They used both the "Stimulated Recall Protocol Technique" and a questionnaire to gather the necessary data for their study. It was found that there were significant differences in the use of strategies between students who were studying English as their main major and students from other majors. They concluded by suggesting some pedagogical implications to help Chinese EFL student writers even those with diverse writing ability improve their writing skills.

\section{Method}

\subsection{Participants}

Thirty six university female students participated in the study. Twenty four of them were taking a content and pedagogy course while the rest of them were following an ESL methodology course with one of the two researchers who was the instructor of both courses at the time of collecting the data. All these students were either in their third or fourth year in the elementary teachers program in the Faculty of Education in the United Arab Emirates University (UAEU). These students hope to become English teachers in public schools after their graduation. Their language proficiency was determined by their scores in the IELTS exam. The majority of them fell in the five-band score while a few of them scored 5.5. The reason for selecting these two groups of students to participate in the study is that they were at that time preparing for their "Content Exam" which includes a writing section. They became more enthusiastic to participate in the study when they were informed that the writing topics would be similar to those topics of the "Content Exam".

\subsection{Instruments}

Three different tools were used to collect the necessary data for answering the three research questions. The first instrument included two writing prompts similar to writing tasks used in standardized writing tests such as the IELTS and TOEFL exams. Both prompts were translated into Arabic to make sure that all participants understand the intent of each topic. Those two topics were expected to be controversial and generate more ideas from students. The two topics are: 1. should foreign language instruction begin in kindergarten? 2. Will modern technology, such as the Internet ever replace the book or the written word as the main source of information?

The second and third instruments were adopted carefully from Cohen's and Brooks- Carson's (2001) study to suit the subjects, purpose and context of the study. The second instrument included a questionnaire regarding the strategies used by students to write the three essays (L2 direct essay, L1 and translated essays). The questionnaire for the first and second essays were identical as they were intended to elicit information for research question 2 which sought to investigate if there are any significant differences between the use of strategies in L1 and L2 writing. The strategy questionnaire for the translated essay included some additional items. Each of the first two questionnaires included 11 items while the third one included 13 items. Each questionnaire was constructed in a five point Likart scale descending from 5 (always) to 1 (never). The third instrument included five follow-up open ended questions to elicit information about students' experience and/or advantages and disadvantages of writing directly in English and translating an essay into English after writing it in Arabic. Only 25 students responded to these questions as 11 of them were absent on that day.

The multi-trait rating scale was carefully adopted from Cohen's and Brooks- Carson's (2001) study to suit the study's purpose and context. The scale was adjusted to assess those features of writing that emphasized the form 
and function of the writing products more than the content and/or the ideas expressed by the students. It included eleven items of five point Likart scale descending from 5 (excellent performance) to 1 (poor performance).

\subsection{Data Collection}

All the data were collected during the second semester of the academic year 2010-2011. During two of the classes of each group, students were given a list of two different topics and instructed to write three essays not exceeding a page for each composition. They were asked to write an essay directly in English and to write the second essay in Arabic and then translate it into English. Direction was given to students to organize their essay by including an introduction, one or two body paragraphs and a conclusion. Time limit (30-40 minutes for each essay) was observed by reminding the students about the allotted time prior to the start of each session. In order to control for order effect, the students were divided into two groups and each group started to write a different essay from the other group. Students were also not permitted to use any tools, such as dictionaries to eliminate the effect of any other variables. After each composition, students were given the relevant questionnaire to elicit the strategies they used. At the end, each student was asked to answer the follow-up questions regarding their opinions about the advantages and disadvantages of direct and translated compositions.

\subsection{Data Analysis}

The direct and translated essays were graded by two ESL competent educators. The first rater was an ESL faculty member who has been heavily involved in teaching ESL writing. The second rater was an experienced high school competent ESL teacher. Initially, a meeting was conducted to give them a thorough idea about the purpose and the nature of the study. Then, a workshop was conducted to discuss the rubrics and show them how to mark each paragraph. Later, a calibration session was conducted to make sure that the two raters were consistent in their evaluation and they have understood and interpreted the rubrics in the same way. They marked all the scripts together on the same table and they sometimes stopped to discuss any discrepancy and reach an agreement. Finally, the inter-rater reliability value was calculated to guarantee an acceptable agreement.

An inter-rater reliability analysis using the Kappa was performed to determine consistency between the two raters for the direct writing essay in English. The inter-rater reliability for the two raters was found to be Kappa .489. As stated in the literature, this value is an indicator of a good inter-rater reliability (Landis, 1977). Also, the inter-raters reliability value for the translated essay (.493) was found to be slightly higher than that of the direct essay (.489). This value is also considered to be a good indicator of raters' consistency.

The average grades for both raters were input into the Statistical Package for Social Sciences program (SPSS 18.0) to obtain descriptive statistics and independent sample t-tests. Similarly, the data collected by the strategy questionnaires for the direct and the L1 essay were input into the SPSS program to obtain descriptive statistics and independent sample t-tests. The qualitative data collected by the follow-up questions were categorized into themes or recurrent patterns. Following a qualitative analysis technique suggested by Patton (2002), the researcher looked at "the details and specifics" of the data collected via the follow-up questions to discover important patterns and themes and interrelationships. The frequencies and percentages for each recurrent pattern were calculated. The data collected about the used strategies for writing the translated essay were put into a table and the frequencies and percentages for each item were also calculated.

\section{Results and Discussion}

Research question 1addressed the issue of students' writing production for both the direct and translated essays. All results in table 1 demonstrate statistically significant differences between the direct and translated essays. All the significant differences are in favor of the direct essay. The overall means for both essays range from 2.83 to 3.42. These results clearly reveal that students performed better when they wrote their essays directly in English. One of the interpretations for having all these interesting and statistically significant results is that those students have always been asked to write their assignments in English and they have very limited chances to translate into Arabic. The above results are in agreement with results reported by Cohen and Brooks-Carson (2001) in their study with students who were studying French as a second language. They found that some students prefer to write directly in French especially when they are under time pressure. The mean performance for students who started writing their essay directly in French was reported to be better than the mean of the other group. However, the mean scores for students who started writing the translated essay were not found to be statistically significant.

The mean scores for item 5 (Clarity of Points) were 3.57 and 3.07 for the direct and translated essay respectively. The result for the direct essay is considered to be an interesting one as it is the highest of all other results. This result reveals that students can write their ideas clearly when composing directly in English. The second highest 
result in favor of the direct essay was the one for the second item (variety of vocabulary). This might be because students felt free to make their choices for the appropriate vocabulary when they thought and wrote their essay directly in English. Since those students did not have sufficient experience in professional translation, they tended to focus on the exact meaning of each word and they ended using limited number of vocabulary in the translated essay. Another interpretation is that those students might not have enough experience in writing in their first language. Many of them tended to organize the translated essay in the same way as they wrote it in Arabic. Woodall (2002) indicated that the differences between the uses of L1 by students may be attributed to students' different writing ability in L1. Good writing ability in L1 may contribute to progressing in learning to write in L2. Woodall (2002) also argued that when writing in L2, students have the experience of two languages that might possess different writing conventions and styles. All these elements interact together during the process of composing in L2 and they may either assist or hinder the accomplishment of the writing task. In line with this argument, Weijen et al (2009) reported that all students used their L1 to some extent while writing L2 tasks. One of their interesting points is that general writing proficiency was found to have negative effect on L1 use during L2 composing and a positive influence on L2 use during the process of writing directly in L2.

The lowest mean score for the translated essay was the one for item 7 (Use of Subordinations). This result highlights students' difficulties in using subordinates to write longer sentences. Some students tried to use subordinates but they ended writing grammatically incorrect sentences. Table 1 also shows other lower mean scores for the translated essay, such as the ones concerning the use of relative pronouns, smoothness of connectors and the use of verbs. When considering the use of relative pronouns in both direct and translated essays, we realize that the number of students who got acceptable scores for this point were very limited. The low mean score for this item clearly shows that students did not do very well in using the relative pronouns. The use of verbs also represented real problems for a considerable number of students. Those difficulties were reflected by a lower mean score (2.76) for this item for the translated essay. Generally, all results of the translated essay demonstrate that students have difficulties with language use. These results of language use are not in agreement with what Uzawa (1996) found in her study about Japanese students who were studying English as a second language in an educational institution in Canada. She reported that the mean score (5.62) of language use in the translation task was better than those scores of the other two tasks (L1 task and direct writing task in L2). The efficient language use by the Japanese students in Uzawa's study might be attributed to the learners' language proficiency and the context of the study.

Table 1. Students' Performance in Direct and Translated Compositions

\begin{tabular}{llllll}
\hline & $\begin{array}{l}\text { Overall } \\
\text { Mean }\end{array}$ & $\begin{array}{l}\text { Direct } \\
\text { Mean }\end{array}$ & $\begin{array}{l}\text { Trans } \\
\text { Mean }\end{array}$ & T-Tests & $\begin{array}{l}\text { Sig. } \\
\text { (2-tailed) }\end{array}$ \\
\hline freedom from translation influence & 3.06 & 3.43 & 2.69 & 5.885 & .000 \\
variety in vocabulary & 3.42 & 3.56 & 3.29 & 2.695 & .009 \\
sense of the language & 3.10 & 3.39 & 2.81 & 4.726 & .000 \\
organizational structure & 3.17 & 3.51 & 2.82 & 5.468 & .000 \\
clarity of points & 3.32 & 3.57 & 3.07 & 3.859 & .000 \\
smoothness of linking words & 2.96 & 3.18 & 2.74 & 4.244 & .000 \\
use of subordinations & 2.85 & 3.07 & 2.63 & 3.853 & .000 \\
use of relative pronouns & 2.83 & 3.00 & 2.67 & 2.582 & .012 \\
use of prepositions/ Articles & 3.11 & 3.32 & 2.90 & 3.821 & .000 \\
noun/adjective agreement & 3.05 & 3.24 & 2.86 & 3.178 & .002 \\
use of verbs & 2.96 & 3.15 & 2.76 & 3.606 & .001 \\
\hline
\end{tabular}

Note. ${ }^{*} \mathrm{p}<0.05$

Research question 2 addressed whether there are any significant differences between students' use of writing strategies in L2 and L1. Table 2 demonstrates no statistically significant result. The overall means for all items range from 2.60 to 4.04 . All overall mean scores are less than 4 except the one for the third item (pay attention to the connecting words you chose to link ideas together $\{\mathrm{M}=4.04\}$ ). This result highlights students' feeling of competence in using this strategy in both languages. Students might have learned to use this strategy in Arabic or English and they perhaps have been capable of transferring it from one language to another. Evidence from the literature can be found in a number of studies that have compared first language and second-language writing 
and have found that there are similarities among the strategies used for both L1 and L2 processes (Jones and Tetroe, 1987; Uzawa and Cumming, 1989; Qi, 1998).

Although the t-tests shows no statistically significant differences between the uses of strategies in both essays, the individual mean scores for item 4 (attempt to use a wide variety of vocabulary) demonstrate some difference in favor of the L1 essay. The mean scores were 4.08 and 3.47 for the L1 essay and the direct essay respectively. This result emphasizes students' confidence to vary their vocabulary when writing in L1. However, insufficient experience in writing directly in L2, language proficiency and thinking in both languages might have contributed to the difficulties students encountered in the choice of vocabulary for the direct essay as compared with the L1 essay. In their study about the differences in L1 use among students of various language proficiency levels, Wang and Wen (2002) found that the lower level writers depend more on L1 than the higher level ones. They argued that L2 writers will rely less and less on the use of their L1 as they continue to develop their L2 language proficiency. The results of this study highlight the gradual development for composing the L2 texts. The development of students' ability to compose texts in L2 can be like a continuum, starting with translation of texts from L1 to L2 and ending with writing direct texts in L2. In line with this argument, Turnbull and Dailey-O'Cain (2009) argued that the use of L1 in classrooms should not substitute or compromise for the importance of second language acquisition. Rather, it should be put into practice to facilitate L2 learning and help learners meet the demands of content area writing tasks (cited in, Kibler, 2010).

Table 2. L1 and L2 Writing Strategies

\begin{tabular}{|c|c|c|c|c|c|}
\hline & $\begin{array}{l}\text { Overall } \\
\text { Mean }\end{array}$ & $\begin{array}{l}\text { L1 } \\
\text { Mean }\end{array}$ & $\begin{array}{l}\text { L2 } \\
\text { Mean }\end{array}$ & $\begin{array}{l}\text { T-Tes } \\
\text { ts }\end{array}$ & $\begin{array}{l}\text { Sig. } \\
\text { (2-taile } \\
\text { d) }\end{array}$ \\
\hline plan out the organization of the essay in advance & 3.88 & 3.78 & 3.97 & -.929 & .356 \\
\hline $\begin{array}{l}\text { plan out the organization of the essay as you went } \\
\text { along }\end{array}$ & 3.56 & 3.64 & 3.47 & .701 & .486 \\
\hline $\begin{array}{l}\text { pay attention to the connecting words you chose to } \\
\text { link ideas together }\end{array}$ & 4.04 & 4.08 & 4.00 & .357 & .722 \\
\hline attempt to use a wide variety of vocabulary & 3.78 & 4.08 & 3.47 & 2.598 & .011 \\
\hline find yourself thinking in English & 2.60 & 2.47 & 2.72 & -.816 & .417 \\
\hline $\begin{array}{l}\text { purposely make use of complex grammatical } \\
\text { structures }\end{array}$ & 2.79 & 2.83 & 2.75 & -.816 & .741 \\
\hline $\begin{array}{l}\text { purposely connect shorter sentences into longer, } \\
\text { complex sentences }\end{array}$ & 3.08 & 3.19 & 2.97 & 1.030 & .306 \\
\hline check for subject-verb agreement in the essay & 3.58 & 3.64 & 3.53 & .461 & .646 \\
\hline $\begin{array}{l}\text { make sure that the negative forms were used } \\
\text { properly }\end{array}$ & 2.96 & 2.97 & 2.94 & .110 & .913 \\
\hline check for adjectives and adverbs use in a sentence & 3.39 & 3.42 & 3.36 & .209 & .835 \\
\hline make sure that the passive forms were used properly & 3.11 & 3.14 & 3.08 & .222 & 825 \\
\hline
\end{tabular}

Note. ${ }^{*} \mathrm{p}<0.05$

Research question 3 examined students' views regarding their experience (advantages and disadvantages) in writing the direct and translated essays. Table 3 demonstrates a number of high percentages extracted from the answers to the follow-up questions for the advantages and disadvantages of writing both essays. The highest percentage (72\%) of students indicated that it is an advantage to write an essay first in L1 and then translate it to English as this procedure may assist in generating more ideas and writing more organized details. Evidence from the literature is found in Stapa's and Abdulmajid's (2009) study which reported that students who initially used their L1 to generate ideas demonstrated better performance when they composed their essay in L2. Another similar result is found in Uzawa's (1996) study in which most participants reported that both translation and L2 writing tasks are helpful for learning and improving a second language. Uzawa (ibid) argued that translation activities may have some benefits for ESL learners as they always pay careful attention to language use during the process of translation from L1 to L2. Wang (2003) also argued that the amount of L1 use when writing in ESL was not reduced as a result of language proficiency improvement. Wang (ibid) pointed out that student writers switch to the $\mathrm{L} 1$ for rhetorical and discourse choices which represent a great help for them. In line with 
this result, Cohen's and Brooks-Carson's (2001) reported that students did better in organizing the translated essay.

When considering the advantages of writing directly in English, a considerable number of students (48\%) agreed that it is easier and quicker for them to think and write directly in English. Some students (32\%) think that they prefer to write directly in English because they follow their study in that language and they feel it is easier for them. A number of students (44\%) also think that writing directly in English will help them improve their writing skill. In Cohen's and Brooks-Carson's (2001) study, the students as a whole group asserted that practicing to compose directly in L2 will ultimately assist them in focusing on French expression and will help them improve their L2 language. They pointed out that they found it easier and even sometimes faster to write directly in French than translating a piece of writing from L1. Also, Cohen and brooks-Carson reported that students with a higher self-assessed index of proficiency in French and students who rated themselves as more proficient in French expressed their preference to write directly in French.

Three major disadvantages for the translated essay were highlighted by a considerable number of students. The first result demonstrates that the majority of students (52\%) think that translation is a very difficult task as they feel confused and find difficulties in organizing their ideas. The second result shows that a number of students (36\%) feel it is hard to find the exact word or expression when translating into English. The third interesting result reveals that some students (32\%) think that their problems in translation are due to the different writing conventions of Arabic and English. Thus, this result is consistent with the reported significant results in table 1.

Table 3. Advantages and Disadvantages of Writing direct and Translated Compositions

Advantages of writing first in L1 and then translating into English

\begin{tabular}{|c|c|c|}
\hline Item & Frequency & $\%$ \\
\hline think and generate ideas & 5 & 20 \\
\hline easy to transfer and think about ideas and then write in English & 5 & 20 \\
\hline assist in getting more ideas and writing more organized details & 18 & 72 \\
\hline the essay can be rich of ideas and vocabulary & 6 & 24 \\
\hline help write quickly and easily & 3 & 12 \\
\hline help connect each paragraph together & 1 & 4 \\
\hline writing in Arabic does not have a lot of rules & 2 & 8 \\
\hline learn more vocabulary in English & 4 & 16 \\
\hline help learners improve their writing & 2 & 8 \\
\hline \multicolumn{3}{|l|}{ Disadvantages of writing first in L1 and then translate into English } \\
\hline $\begin{array}{l}\text { difficult to translate into English and get confused when organizing the translated } \\
\text { essay }\end{array}$ & 13 & 52 \\
\hline difficulty in translating some words into English & 3 & 12 \\
\hline wasting time in translation & 6 & 24 \\
\hline difficult to find the exact meaning of words or expression in English & 9 & 36 \\
\hline the two languages have different ways of writing & 8 & 32 \\
\hline $\begin{array}{l}\text { not used to write in Arabic and have already forgotten how to write and organize } \\
\text { ideas in Arabic }\end{array}$ & 2 & 8 \\
\hline cannot remember some vocabulary in Arabic & 1 & 4 \\
\hline \multicolumn{3}{|l|}{ Advantages of writing directly in English } \\
\hline easier and quicker to write ideas directly in English & 12 & 48 \\
\hline easy to write in English as a result of studying in English & 8 & 32 \\
\hline saving time when writing directly in English & 7 & 28 \\
\hline improving English writing skills & 11 & 44 \\
\hline controlling ideas & 3 & 12 \\
\hline making a few mistakes & 1 & 4 \\
\hline writing without thinking about translation & 1 & 4 \\
\hline helping us evaluate our writing & 2 & 8 \\
\hline \multicolumn{3}{|l|}{ Disadvantages of writing directly in English } \\
\hline difficult to organize ideas & 2 & 8 \\
\hline difficult to choose topics & 1 & 4 \\
\hline
\end{tabular}


Research question 4 dealt with the most frequent strategies students indicated to have used in writing the translated essay. Table 4 demonstrates a number of interesting results about specific strategies students agreed to have used during the process of writing their translated essay. A great number of students $(69 \%)$ indicated that they always or often try to make an effort to think how best to express their ideas in English. However, writing directly in English may not offer them this opportunity to think about a better way for expressing their ideas in L2. In line with this result, Stapa and Abdulmajid (2009) argued in favor of the use of the L1 as they found that students who initially used their L1 to generate ideas demonstrated better performance when they composed their essay in L2. They reiterated that writing is a complex cognitive activity, so that teachers and educators should take all the necessary measures to facilitate the process of learning how to write in L2, including the use of L1 and/or translation.

Another interesting result shows that a great number (69\%) of students indicated that they always or often attempted to find the best connecting words suitable for linking ideas together. When comparing the strategies used by students for L1 essay and L2 direct essay, it was found that there is no significant difference between the uses of this strategy in the two essays (see table 2). However, when considering their performance in this item, students' scores for the direct essay were found to be better than their scores for the translated one. Generally, this result clearly highlights the difficulty students find in using the right connectors. In their translated essay it was realized that many students avoided using any kind of connectors. This might be attributed to the nature of the translation they conducted in writing the translated essay. As a result of translating the essay sentence by sentence, students might ignore the issue of connecting those sentences and organizing them according to English language writing conventions. Many students (69\%) pointed out that they always or often try to change the organization to fit the English language system when translating from L1 to L2. In Cohen's and Brooks-Carson's (2001) study, students reported that "sometimes" they attempted to change the organization of the French text (L2) in order to fit the organization of the English essay (L1) when conducting the translation process. The less frequent change students conducted in the later study might be attributed to the similarities between English and French organizational systems.

Table 4. Translated Composition Strategies

\begin{tabular}{|c|c|c|c|c|c|c|c|c|c|c|}
\hline & \multicolumn{2}{|l|}{$\begin{array}{l}5 \\
\text { Alw }\end{array}$} & \multicolumn{2}{|c|}{$\begin{array}{l}4 \\
\text { Usually }\end{array}$} & \multicolumn{2}{|c|}{$\begin{array}{l}3 \\
\text { Sometimes } \\
\end{array}$} & \multicolumn{2}{|c|}{$\begin{array}{l}2 \\
\text { Rarely }\end{array}$} & \multicolumn{2}{|c|}{$\begin{array}{l}1 \\
\text { Never }\end{array}$} \\
\hline & Frq & $\%$ & Frq & $\%$ & Frq & $\%$ & Frq & $\%$ & Frq & $\%$ \\
\hline $\begin{array}{l}\text { stick to the organization used in the first } \\
\text { essay }\end{array}$ & 9 & 25.0 & 12 & 33.3 & 8 & 22.2 & 4 & 11.1 & 3 & 8.3 \\
\hline $\begin{array}{l}\text { change the organization somewhat to fit the } \\
\text { English language writing convention }\end{array}$ & 8 & 22.2 & 16 & 44.4 & 8 & 22.2 & 3 & 8.3 & 1 & 2.8 \\
\hline $\begin{array}{l}\text { attempt to find the best connecting words } \\
\text { used to link ideas together }\end{array}$ & 12 & 33.3 & 13 & 36.1 & 9 & 25.0 & 2 & 5.6 & & \\
\hline $\begin{array}{l}\text { make an effort to think how best to express } \\
\text { the ideas in English }\end{array}$ & 10 & 27.8 & 15 & 41.7 & 8 & 22.2 & 1 & 2.8 & 2 & 5.6 \\
\hline avoid translating word-for-word & 14 & 38.9 & 7 & 19.4 & 13 & 36.1 & 1 & 2.8 & 1 & 2.8 \\
\hline $\begin{array}{l}\text { have difficulty finding translation } \\
\text { equivalents in English for words in the } \\
\text { essay }\end{array}$ & 3 & 8.3 & 7 & 19.4 & 15 & 41.7 & 8 & 22.2 & 3 & 8.3 \\
\hline $\begin{array}{l}\text { find yourself using simpler words and } \\
\text { structures in English }\end{array}$ & 5 & 13.9 & 13 & 36.1 & 16 & 44.4 & 2 & 5.6 & & \\
\hline attempt to use a wide variety of vocabulary & 4 & 11.1 & 9 & 25.0 & 17 & 47.2 & 5 & 13.9 & 1 & 2.8 \\
\hline $\begin{array}{l}\text { purposely make use of complex } \\
\text { grammatical structures }\end{array}$ & 1 & 2.8 & 6 & 16.7 & 10 & 27.8 & 16 & 44.4 & 3 & 8.3 \\
\hline $\begin{array}{l}\text { check for subject-verb agreement in the } \\
\text { essay }\end{array}$ & 4 & 11.1 & 10 & 27.8 & 14 & 38.9 & 7 & 19.4 & 1 & 2.8 \\
\hline $\begin{array}{l}\text { make sure that the negative forms were used } \\
\text { properly }\end{array}$ & 2 & 5.6 & 6 & 16.7 & 17 & 47.2 & 9 & 25.0 & 2 & 5.6 \\
\hline $\begin{array}{l}\text { check for adjective agreement in gender and } \\
\text { number }\end{array}$ & 4 & 11.1 & 7 & 19.4 & 17 & 47.2 & 8 & 22.2 & & \\
\hline $\begin{array}{l}\text { make sure that the passive forms were used } \\
\text { properly }\end{array}$ & 2 & 5.6 & 11 & 30.6 & 19 & 52.8 & 3 & 8.3 & 1 & 2.8 \\
\hline
\end{tabular}




\section{Recommendations}

The present study highlighted a number of important results regarding the advantages and disadvantages of writing directly in L2 and translated writing from L1 to L2. Those results helped in extracting the following instructional recommendations. Teachers should expose students directly to the norms of writing in L2 and provide them with enough and continuous opportunities to practice writing in different genres in L2. At early stages, teachers should explicitly highlight the differences between the norms of writing in L1 and L2 as writing in Arabic is to some extent different from writing in English. Students should always be encouraged to reflect on their writing experience in L2 and they should always be encouraged to use their first language writing experience when writing in L2. Finally, students should be helped to become aware of the strategies they use when writing in L1 and they should be taught how to transfer and use those strategies when writing in L2.

\section{Conclusion}

This study examined students' performance and strategies in writing a direct and a translated composition. It also investigated students' views regarding the advantages and disadvantages of both compositions. Two prompts were used for writing the required essays. Also a questionnaire was distributed after each essay to elicit the kinds of strategies students used in writing the different essays. The findings of the study demonstrate statistically significant differences between the direct and the translated essay. Interestingly, all the findings are in favor of the essay written directly in English. All these results highlight the importance of exposing ESL/EFL student writers directly to the norms of writing in L2. However, the results of the strategy questionnaire reveal no statistically significant differences between the direct and the L1 compositions. This indicates that students may transfer L1 writing strategies when writing in L2 and vice versa. The analysis of the qualitative data collected by the follow-up questions demonstrates positive attitudes toward the task written directly in English. Most of the results extracted from the qualitative data are consistent with the results obtained from the quantitative data. While analyzing the data, certain important issues, which were not accounted for in the research design, emerged surprisingly, such as the issues of translation and L1 writing proficiency. Hence, these issues need to be further investigated in the future to understand their impact on students' L2 writing. Moreover, research in the future may focus on comparing the writing strategies students claimed to have used in writing the different essays and the actual use of such strategies.

\section{Acknowledgement}

This research project was funded by the Research Affairs at the UAE University under a contract no. 08-01-11-2011 with the first author. The researchers would like to thank the Research Affairs at the UAE University for supporting this study financially.

\section{References}

Abu Rass, R. (2011). Cultural transfer as an obstacle for writing well in English: The case of Arabic speakers writing in English. English language Teaching, 4(2), 206-212.

Akyel, A. (1994). First language use in EFL writing: Planning in Turkish vs. planning in English. International Journal of Applied Linguistics, 4, 169-197. http://dx.doi.org/10.1111/j.1473-4192.1994.tb00062.x

Al-Khatib, M. (2001). The pragmatics of letter writing. World Englishes, 20(2), 179-200. http://dx.doi.org/10.1111/1467-971X.00208

Alsamadani, H. A. (2010). The Relationship between Saudi EFL Students' Writing Competence, L1 Writing Proficiency, and Self-regulation. European Journal of Social Sciences, 16(1), 53-63.

Baker, B. A. (2008). L2 writing and L1 composition in English: Towards an alignment of Effort. McGill Journal of Education, 43(2), 139-155. http://dx.doi.org/10.7202/019579ar

Beare, S. (2000). Differences in content generating and planning processes of adult L1and L2 proficient writers. Unpublished doctoral dissertation, University of Ottawa, Ottawa, Ontario.

Beare, S., \& Bourdages, J. S. (2007). Skilled writers' generating strategies in L1 and L2: An exploratory study. In G. Rijlaarsdam (Series Ed.) \& M. Torrance, L. VanWaes, and D. Galbraith (Vol. Eds.). Studies in Writing, 20, Writing and Cognition: Research and Applications (pp. 151-161). Amsterdam: Elsevier.

Casanave, C. P. (2002). Writing games: Multicultural case studies of academic literacy practices in higher education. Mahwah, NJ: Lawrence Erlbaum Associates.

Cohen, A. D. (1998). Strategies in Learning and Using a Second Language. Harlow: Longman. 
Cohen, A., \& Brooks-Carson, A. (2001). Research on direct versus translated writing: Students' strategies and their results. The Modern Language Journal, 85(2), 169-188. http://dx.doi.org/10.1111/0026-7902.00103

Connor, U. (2002). New Directions in Contrastive Rhetoric. TESOL Quarterly, 36(4), 493-510. http://dx.doi.org/10.2307/3588238

Dyc, G. (2002). Language learning in the American Southwestern borderlands: Navajo speakers and their transition to academic English literacy. Bilingual Research Journal, 26(3), 611-630. http://dx.doi.org/10.1080/15235882.2002.10162581

F, B., \& Jimenez, A. (2004). Problem-solving tasks in a foreign language: The importance of the L1 in private verbal thinking. International Journal of Applied Linguistics, 14, 7-35.

Friedlander, A. (1990). Composing in English: Effects of a first language on writing in English as a second language. In B. Kroll (Ed.), Second language writing: Research insights for the classroom (pp. 109-125). Cambridge: Cambridge University Press.

Griffiths, C. (2007). Language learning strategies: students' and teachers' perceptions. ELT Journal, 61(2), 91-99. http://dx.doi.org/10.1093/elt/ccm001

Ismail, S. (2011). Exploring students' perceptions of ESL writing. English Language Teaching, 4(2), 73-83.

Jones, S., \& Tetroe, J. (1987). Composing in a second language. In A. Matsuhashi (Ed.), Writing in real time: Modeling production processes (pp. 34-57). Norwood, NJ: Ablex.

Kamimura, T. (2001). Japanese students' L1-L2 writing connections: Written texts, writing competence, composing processes, and writing attitudes. The Bulletin of the Kanto-Koshin-Etsu English Language Education Society, 15, 165-183.

Khuwaileh, A. A., \& Shoumali, A. A. (2000). Writing errors: A study in writing ability of Arabic learners of academic English and Arabic at university. Language, culture and curriculum. 13(2), 174-183. http://dx.doi.org/10.1080/07908310008666597

Kibler, A. (2010). Writing through two languages: First language expertise in a language minority classroom. Journal of Second Language Writing, 19(3), 121-142. http://dx.doi.org/10.1016/j.jslw.2010.04.001

Kobayash, H., \& Rinnert, C. (2008). Task responses and task construction across L1 and L2 writing. Journal of Second Language Writing, 17(1), 7-29. http://dx.doi.org/10.1016/j.jslw.2007.08.004

Kobayashi, H., \& Rinnert, C. (1992). Effects of first language on second language writing: Translation versus $\begin{array}{llll}\text { direct composition. } & \text { Language } & \text { Learning, } & \text { 42(2), }\end{array}$ http://dx.doi.org/10.1111/j.1467-1770.1992.tb00707.x

Kohro, Y. (2009). A contrastive study between L1 and 12 composition: Focusing on global text structure, composition quality and variables in L2 writing. Dialogue, 8, 1-19.

Krapels, A. R. (1990). An overview of second language writing process research. In B. Kroll (Ed.), Second language writing: Research insights for the classroom (pp. 37-56). Cambridge: Cambridge University Press.

Lally, C. G. (2000). First language influences in second language composition: The effect of pre-writing. Foreign Language Annals, 33(4), 428-432. http://dx.doi.org/10.1111/j.1944-9720.2000.tb00623.x

Landis, J. R., \& Koch, G.G. (1977). The measurement of observer agreement for categorical data. Biometrics 33(1), 159-174. http://dx.doi.org/10.2307/2529310

Lei, X. (2008). Exploring a sociocultural approach to writing strategy research: Mediated action in writing activities. Journal of Second Language Writing, 17(4), 217-236. http://dx.doi.org/10.1016/j.jslw.2008.04.001

Leki, I. (2000). Writing, literacy and applied linguistics. Annual review of Applied Linguistics, 20, 99-115. http://dx.doi.org/10.1017/S0267190500200068

Lv, F., \& Chen, H. (2010). A Study of Metacognitive-Strategies-Based Writing Instruction for Vocational College Students. English Language Teaching, 3(3), 136-144.

Martínez, I. A. (2005). Native and non-native writers' use of first person pronouns in the different sections of biology research articles in English. Journal of Second Language Writing, 14(3), 174-190. http://dx.doi.org/10.1016/j.jslw.2005.06.001 
McCarthey, S. J., et al. (2005). Understanding changes in elementary Mandarin students' L1 and L2 writing. Journal of Second Language Writing, 14(2), 71-104. http://dx.doi.org/10.1016/j.jslw.2005.05.003

Patton, M. Q. (2002). Qualitative research and evaluation methods (3rd ed.). Thousand Oaks, CA: Sage Publications, Inc.

Qi, D. S. (1998). An inquiry into language-switching in second language composing processes. The Canadian Modern Language Review/La Revue canadienne des langues vivantes, 54, 413-435.

Ramanathan, V., \& Kaplan, R. B. (1996). Audience and voice in current L1 composition texts: Some implications for ESL student writers. Journal of Second Language Writing, 5(1), 21-34. http://dx.doi.org/10.1016/S1060-3743(96)90013-2

Roca de Larios, J., Murphy, L., \& Manchon, R. (1999). The use of restructuring strategies in EFL writing: A study of Spanish learners of English as a foreign language. Journal of Second Language Writing, 8(1), 13-44. http://dx.doi.org/10.1016/S1060-3743(99)80111-8

Sasaki, M. (2004). A multi-data analysis of the 3.5-year development of EFL student writers. Language Learning, 54(3), 525-582. http://dx.doi.org/10.1111/j.0023-8333.2004.00264.x

Sasaki, M. (2007). Effects of study-abroad experiences on EFL writers: A multiple-data analysis. The Modern Language Journal, 91(4), 602-620. http://dx.doi.org/10.1111/j.1540-4781.2007.00625.x

Stapa, S. H., \& Abdulmajid, A. (2009). The Use of First Language in Developing Ideas in Second Language Writing. European Journal of Social Sciences, 7(4), 41-47.

Turnbull, M., \& Dailey-O'Cain, J. (2009a). Introduction. In M. Turnbull and J. Dailey-O'Cain (Eds.), First language use in second and foreign language learning (pp. 1-14). Bristol: Multilingual Matters.

Uzawa, K. (1996). Second language learners' processes of L1 writing, L.2 Writing, and Translation from L1 into L2. Journal of Second Language Writing, 5(3), 271-294. http://dx.doi.org/10.1016/S1060-3743(96)90005-3

Uzawa, K., \& Cumming, A. (1989). Writing strategies in Japanese as a foreign language: Lowering or keeping up the standards. The Canadian Modern Language Review/La Revue canadienne des langues vivantes, 46, 178-194.

Wang, L. (2003). Switching to first language among writers with differing second-language proficiency. Journal of Second Language Writing, 12(4), 347-375. http://dx.doi.org/10.1016/j.jslw.2003.08.003

Wang, W., \& Wen, Q. (2002). L1 use in the L2 composing process: An exploratory study of 16 Chinese EFL writers. Journal of Second Language Writing, 11(3), 225-246. http://dx.doi.org/10.1016/S1060-3743(02)00084-X

Weijen, D., et al. (2009). L1 use during L2 writing: An empirical study of a complex phenomenon. Journal of Second Language Writing, 18(4), 235-250. http://dx.doi.org/10.1016/j.jslw.2009.06.003

Wenyu, L., \& Yang, L. (2008). Research on EFL writing strategy using SRP: An empirical study in DUT. The Asian EFL Journal, 10(2), 51-83.

Wolfersberger, M. (2003). L1 to L2 Writing Process and Strategy Transfer: A Look at Lower Proficiency Writers. TESL-EJ, 7(2), 1-12.

Wong, A. T. Y. (2005). Writers' mental representation of the intended audience and of the rhetorical purpose for writing and the strategies that they employed when they composed. System, 33, 29-47. http://dx.doi.org/10.1016/j.system.2004.06.009

Woodall, B. R. (2002). Language switching: using the first language while writing in a second language. Journal of Second Language Writing, 11(1), 7-28. http://dx.doi.org/10.1016/S1060-3743(01)00051-0

Xiaoxia, L. (2008). Literature review on the use and effect of L1 in L2 writing. US-China Foreign Language, $6(5), 50-53$.

Zainuddin, H., \& Moore, R. (2003). Audience Awareness in L1 and L2 Composing of Bilingual Writers, ESL-EJ, 7(1), 1-19.

Zare-ee, A., \& Farvardin, M. (2009). Comparison of university level EFL learners' linguistic and rhetorical patterns as reflected in their L1 and L2 writing. Novitas-ROYAL, 3(2), 143-155.

Zhang, D., \& Goh, C. (2006). Strategy knowledge and perceived strategy use: Singaporean students' awareness of listening and speaking strategies. Language Awareness, 15(3), 199-219. http://dx.doi.org/10.2167/la342.0 